\title{
A Comparative Study of Motor Ability between Elite Basketball Players from Different Regions
}

\author{
Velisa Vukasevic', Milena Mitrovic ${ }^{2}$ and Bojan Masanovic ${ }^{2}$ \\ 'Basketball Club Vizura, Belgrade, Serbia, ${ }^{2}$ University of Montenegro, Faculty for Sport and Physical Education, Niksic, Montenegro
}

\section{Abstract}

The purpose of this research was to describe the motor abilities of basketball players from the elite ranking of competition in Montenegro and Serbia, and to make a comparison between them. The sample included 48 participants divided into two sub-samples. The first sub-sample comprised 24 participants who were competing in the First Basketball League of Montenegro and the second sub-sample comprised 24 participants competing in the Serbian Super League. Standardized tests were used to assess motor abilities. For each variable, the central and dispersion parameters were calculated. The differences were determined using a t-test for small independent samples. The results showed that a significant difference was found for distance ball throwing, while no significant difference was present for the remaining variables. Therefore, the results indicate that Montenegrin basketball players have well-developed motor abilities and, in this characteristic, do not lag behind Serbian players.
\end{abstract}

Keywords: basketball players, motor ability, different regions

\section{Introduction}

At the end of 1891, Canadian physician and physical education professor James Naismith adapted several sport branches and formed a single unit, wrote simple rules and created a new sport: basketball. Throughout its history, it has become a globally popular sport that engages many people regardless of age, gender, race, or continent in which they live (Narazaki, Berg, Stergiou, \& Chen, 2009; Masanovic, 2018). However, as a professional sport, basketball is characterized by the complexity and high tempo of the game (Dogan \& Ersoz, 2019), as well as the dynamism, variability, and atypicality of the game characterized by rapid continuous reactions in all stages of the match (Trninic, Perica, \& Dizdar, 1999; Saavedra et al., 2018). Such a complex activity can be realized only with the involvement of several factors. The set of factors on which the success of basketball depends are morphological characteristics, motor abilities, functional abilities and psychological characteristics (Narazaki et al., 2009). Numerous studies show that motor abilities are crucial for achieving sport results (Gardašević, Georgiev, \& Bjelica, 2012; Popovic, Bjelica, Jaksic, \& Hadzic,
2014; Sermaxhaj, Popovic, Bjelica, Gardasevic, \& Arifi, 2017; Gusic, Popovic, Molnar, Masanovic, \& Radakovic, 2017; Balaban, 2018; Arifi, Bjelica, \& Masanovic, 2019; Gardasevic, Akpinar, Popovic, Bjelica, 2019). Motor abilities are those competences that contribute to solving motor assignments and condition successful movement, regardless of whether they have been acquired by training or not (Malacko, 2000; Bjelica, 2006a; Bjelica, 2006b; Gardasevic, Bjelica, \& Corluka, 2018; Gjonbalaj, Georgiev, \& Bjelica, 2018; Gardasevic \& Bjelica, 2019). Analysis of the basketball game determined the structure of the most crucial motor abilities for basketball: speed, strength, precision, balance, flexibility and coordination (Karalejić \& Jakovljević, 1998).

One of the most essential segments of the basketball game is the fast-paced abilities of basketball players, which include rebound and agility (Bjelica, 2005; Jakovljevic, Karalejic, Pajic, \& Mandic, 2011; Masanovic, 2019). They allow basketball players efficient movement during the game and, in the equation of the specification, their contribution is as much as $30 \%$ (Berria, Bachir, Nour Eddine, \& Adel, 2018). A factor that largely determines success in

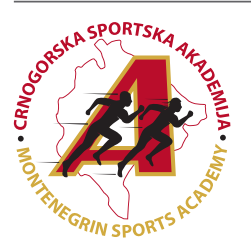

Correspondence: 
basketball is explosive power, manifested in jumps, initial acceleration, rapid changes in direction, deceleration and passing (Delextrat \& Cohen, 2009). Stamina is a essential ability that enables the generation of energy necessary for all kinds of muscular activities, i.e., is the basis of the so-called energy-motor preparation of basketball players (ValdésBadilla, Godoy-Cumillaf, Herrera-Valenzuela, \& RamírezCampillo, 2015). High aerobic ability ensures slower fatigue and faster recovery in short pauses during the game, while anaerobic ability is responsible for durability in repetitive high-intensity activities (B.R. Matković, B. Matković, \& Knjaz, 2005; Bjelica, Popovic, \& Gardasevic, 2016).

The main goals of this research were to determine whether there are differences in the level of motor skills between the players of the First League of Montenegro and the players of the Super League of Serbia, and to determine whether the players who perform in the First League of Montenegro have good motor potential, i.e., if their motor potential lags behind players from Serbia who achieve exceptionally excellent results at the most prominent international competitions.

\section{Methods}

The sample of respondents comprised 48 basketball players of senior age, who play in top-quality teams, divided into two sub-samples. The first sub-sample consisted of 24 basketball players who play in the First League of Montenegro, with an average age of $24.75 \pm 4.24$ years, while the second sub-sample consisted of 24 basketball players who play in the Super League of Serbia, with an average age of $25.08 \pm 5.56$ years.

For the assessment of the motor status, nine standard motor tests were applied, which in previous studies were determined to carry relevant information on the fitness condition of the basketball players (Karalejić \& Jakovljević, 1998). Movement tasks have been chosen to cover all the essential physical characteristics of an athlete and an ever-increasing topographic muscular region. For assessment of speed, a $20 \mathrm{~m}$-high start running test was used. For assessment of explosive strength, the following tests were used: distance ball throwing, vertical jump-Sargent, and standing triple jump. For the assessment of speed endurance, a 30-second sit-up test and push-ups were used. For agility assessment, $4 \times 5 \mathrm{~m}$ running test and $\mathrm{T}$ drill test were used, while durability was assessed using a suicide test.

Testing was done just before the start of the competition season. The condition for participation in the experiment was optimal psychophysical health, a minimum of five years of active training and playing, as well as having played $70 \%$ of the games in the previous season. Respondents volunteered to participate in the experiment, and they were also able to revoke their participation in testing at any time, but none of them decided to do so.

The data obtained in the research were processed using descriptive and comparative statistical procedures. For each variable, central and dispersion parameters were processed, as well as measures of curvature and elongation. Differences in the motor skills of basketball players in the First League of Montenegro and the Super League of Serbia were determined using a discriminative parametric procedure, $\mathrm{t}$-test for small independent samples, with a statistical significance of $\mathrm{p}<0.05$. All statistical analyses were conducted using SPSS software version 20.0 (Chicago, IL, USA).

\section{Results}

In Tables 1 and 2, the basic descriptive statistical parameters of the motor skills of basketball players of the two countries are presented; the calculated values of the central and dispersion tendencies are as follows: arithmetic mean (Mean), standard deviation (Std. Dev.), variance (Variance), minimal (Min) and maximal (Max) values, coefficient of curvature (Skewness) and elongation (Kurtosis).

Table 1. Central and dispersion parameters of variables for the assessment of the motor abilities of basketball players from the First League of Montenegro $(\mathrm{N}=24)$

\begin{tabular}{lcccccc}
\hline \multicolumn{1}{c}{ Variables } & Min & Max & Mean \pm S.D. & Var & Skewness & Kurtosis \\
\hline 20m high start running & 2.87 & 3.65 & $3.24 \pm .22$ & .05 & .407 & -.727 \\
Distance ball throwing & 16.70 & 22.20 & $18.97 \pm 1.53$ & 2.35 & .561 & -.254 \\
Vertical jump & 47.00 & 65.00 & $58.21 \pm 5.68$ & 32.26 & -.676 & -.675 \\
Standing triple jump & 6.50 & 8.45 & $7.61 \pm .57$ & .33 & -.620 & -.512 \\
Sit-up for 30s & 29.00 & 42.00 & $35.67 \pm 3.75$ & 14.06 & -.077 & -.944 \\
Push-ups & 6.00 & 23.00 & $14.33 \pm 4.64$ & 21.54 & -.254 & -.783 \\
4X5m running & 6.00 & 8.00 & $6.97 \pm .34$ & .12 & -.858 & 1.479 \\
T drill & 8.50 & 10.20 & $9.08 \pm .46$ & .21 & 1.068 & .568 \\
Suicides & 25.81 & 30.50 & $27.62 \pm 1.25$ & 1.55 & .714 & -.031 \\
\hline
\end{tabular}

Legend: Min-Minimal value; Max-Maximal value; Mean-Arithmetic mean; S.D.-Standard deviation; Var-Variance; Skewness-Measure of asymmetry; Kurtosis-Measure of flattening

Based on the values of Skewness and Kurtosis, differences in the distribution of results are observed. Skewness has a positive sign in distance ball throwing and negative sing in $4 \times 5 \mathrm{~m}$ running, which indicates that these results are lower from the mean value, among the lower values. For other variables, according to the results of the skewness, we observe better results from the mean value, i.e., among the higher val- ues. Kurtosis has a positive sign in just two variables ( $\mathrm{T}$ drill test and running $4 \times 5$ metres), in which case the distribution of the results is leptokurtic, which means that there are more results accumulated around the distribution centre. In other variables, Kurtosis has a negative sign, so the distribution of results is platykurtic, and more results are accumulated in the tails of the distribution. 
Table 2. Central and dispersion parameters of variables for the assessment of motor abilities of basketball players from Super League of Serbia $(\mathrm{N}=24)$

\begin{tabular}{lcccccc}
\hline \multicolumn{1}{c}{ Variables } & Min & Max & Mean \pm S.D. & Var & Skewness & Kurtosis \\
\hline 20m high start running & 2.81 & 3.62 & $3.20 \pm .23$ & .05 & .099 & -.958 \\
Distance ball throwing & 16.00 & 21.10 & $18.09 \pm 1.31$ & 1.72 & .204 & -.172 \\
Vertical jump & 52.00 & 73.00 & $60.50 \pm 5.37$ & 28.87 & .436 & -.447 \\
Standing triple jump & 6.90 & 8.60 & $7.73 \pm .46$ & .21 & -.28 & -.208 \\
Sit-up for 30s & 30.00 & 42.00 & $36.00 \pm 3.44$ & 11.83 & .098 & -.602 \\
Push-ups & 7.00 & 28.00 & $15.46 \pm 5.82$ & 33.82 & .521 & -.66 \\
4×5m running & 6.00 & 7.00 & $6.91 \pm .36$ & .13 & -.331 & -.869 \\
T drill & 8.50 & 10.48 & $9.06 \pm .52$ & .27 & 1.368 & 1.758 \\
Suicides & 25.71 & 31.52 & $27.92 \pm 1.55$ & 2.40 & .761 & -.051 \\
\hline
\end{tabular}

For the basketball players from the Serbian Super League, Skewness, and Kurtosis values also indicate differences in the distribution of results. Skewness shows a positive asymmetric in distance ball throwing, vertical jump, sit-up for 30s, and push-ups while showing a negative asymmetric distribution in the running $4 \times 5$ metres variables, which means that these results are lower from the mean value, among the lower values.

For other variables, according to the results of the skewness, we observe better results from the mean value, among the high- er values. Positive Kurtosis, i.e., leptokurtic distribution, has only one variable ( $\mathrm{T}$ drill test), which means that we have more results accumulated around the arithmetic centre. Other variables have negative Kurtosis and platykurtic distribution, and more results are accumulated in the tails of the distribution.

To determine whether there are statistically significant differences in the analysed variables of elite basketball players of these two countries, the statistical procedure t-test was applied (Table 3).

Table 3. Differences between the arithmetic means of the variables for assessing the motor abilities of basketball players of the First League of Montenegro $(\mathrm{N}=24)$ and Super League of Serbia $(\mathrm{N}=24)$

\begin{tabular}{|c|c|c|c|c|c|c|}
\hline Variable & Country & Mean \pm S.D. & S.E. & t-test & Sig. & M.D. \\
\hline \multirow{2}{*}{$20 \mathrm{~m}$ high start running } & Montenegro & $3.24 \pm .22$ & .045 & \multirow{2}{*}{.571} & \multirow{2}{*}{.571} & \multirow{2}{*}{.037} \\
\hline & Serbia & $3.20 \pm .23$ & .045 & & & \\
\hline \multirow{2}{*}{ Distance ball throwing } & Montenegro & $18.97 \pm 1.53$ & .313 & \multirow{2}{*}{2.126} & \multirow{2}{*}{.039} & \multirow{2}{*}{.875} \\
\hline & Serbia & $18.09 \pm 1.31$ & .267 & & & \\
\hline \multirow{2}{*}{ Vertical jump } & Montenegro & $58.21 \pm 5.68$ & 1.159 & \multirow{2}{*}{-1.436} & \multirow{2}{*}{.158} & \multirow{2}{*}{-2.292} \\
\hline & Serbia & $60.50 \pm 5.37$ & 1.097 & & & \\
\hline \multirow{2}{*}{ Standing triple jump } & Montenegro & $7.61 \pm .57$ & .116 & \multirow{2}{*}{-.768} & \multirow{2}{*}{.446} & \multirow{2}{*}{-.115} \\
\hline & Serbia & $7.73 \pm .46$ & .094 & & & \\
\hline \multirow{2}{*}{ Sit-up for 30s } & Montenegro & $35.67 \pm 3.75$ & .765 & \multirow{2}{*}{-.321} & \multirow{2}{*}{.750} & \multirow{2}{*}{-.333} \\
\hline & Serbia & $36.00 \pm 3.44$ & .702 & & & \\
\hline \multirow{2}{*}{ Push-ups } & Montenegro & $14.33 \pm 4.64$ & .947 & \multirow{2}{*}{-.741} & \multirow{2}{*}{.463} & \multirow{2}{*}{-1.125} \\
\hline & Serbia & $15.46 \pm 5.82$ & 1.187 & & & \\
\hline \multirow{2}{*}{$4 \times 5 m$ running } & Montenegro & $6.97 \pm .34$ & .071 & \multirow{2}{*}{.538} & \multirow{2}{*}{.593} & \multirow{2}{*}{.055} \\
\hline & Serbia & $6.91 \pm .36$ & .074 & & & \\
\hline \multirow{2}{*}{ Tdrill } & Montenegro & $9.08 \pm .46$ & .093 & \multirow{2}{*}{.153} & \multirow{2}{*}{.879} & \multirow{2}{*}{.022} \\
\hline & Serbia & $9.06 \pm .52$ & .107 & & & \\
\hline \multirow{2}{*}{ Suicides } & Montenegro & $27.62 \pm 1.25$ & .254 & \multirow{2}{*}{-.739} & \multirow{2}{*}{.463} & \multirow{2}{*}{-.300} \\
\hline & Serbia & $27.92 \pm 1.55$ & .316 & & & \\
\hline
\end{tabular}

Legend: Country-Subsample affiliation; Mean-Arithmetic mean; S.D.-Standard deviation; S.E.-Standard error; $t$-t test value; Sig-Statistical significance; M.D.-Mean difference

Based on the values obtained with the t-test, it can be observed that there is a statistically significant difference in the variables of distance ball throwing, and it is in favour of basketball players who play in the First League of Montenegro. In other variables, there is no statistically significant difference in the level of motor skills between the basketball players of the First League of Montenegro and the Super League of Serbia at the level of significance $\mathrm{p}<0.05$.

\section{Discussion}

The results of descriptive statistics show that the players of both examined groups achieved roughly the same results in tests of motor abilities. Players who play in the First League of Montenegro have achieved better results in four tests, while in five tests they were slightly weaker than players of the Super League of Serbia. A statistically significant difference in favour of the players of the First League of Montenegro appears in the 
variable of distance ball throwing, in other tests, a significant difference was not found.

If the results of players covered by this study are compared with the results of professional players from other European countries, we will note that they are generally equal with them or better than them. For example, professional players from Norway ran a distance of 20 metres at an average of 3.2 seconds (Shalfawi, Sabbah, Kailani, Tønnessen, \& Enoksen, 2011), players from Croatia in 3.2 seconds (Milanović, Jukić, \& Marković, 2004) while the basketball players from Super League of Serbia ran the same distance for the average time of 3.2 seconds, while the players from the First League of Montenegro in 3.24 seconds, which is very similar. We observe that the same group of professional players of Norway, although equal in running, in the values of the vertical jump is lagging much behind the players of the elite Leagues of Montenegro and Serbia. The height of the average Norwegian jump is $48.2 \mathrm{~cm}$, which is considerably lower than the $60.50 \mathrm{~cm}$ of Serbian Super League players and $58.21 \mathrm{~cm}$ of players from the Montenegrin First League. Also, significantly lower results on the same test were achieved by professional Tunisian players with a $49.5 \mathrm{~cm}$ jump (Chaouachi et al., 2009). These results are far lower than those obtained by players in the NBA league, which measured the average value of a vertical jump of 72.9 centimetres (Hoffman, 2006), which is not a surprise given that it is the highest quality basketball league in the world. Something similar is seen in the $\mathrm{T}$ drill test for the evaluation of agility, where the average running result of players of the First League of Montenegro ( 9.06 seconds) and Super League of Serbia (9.08 seconds), is slightly higher than the result of the professional players from Tunisia, resulting in 9.7 seconds (Chaouachi et al., 2009), and players who play in the strongest league in Turkey, which is 9.25 seconds (Alemdaroglu, 2012). However, the players from the elite league of Bulgaria have accomplished a better result than all the mentioned groups. Their average running time is 8.52 seconds. Finally, regarding specific basketball endurance, players from both subsamples showed better average values in the suicide test, because the time of 27.6 seconds for players from the Montenegrin First League and 27.9 seconds for players from the Serbian Super League, is slightly faster than the average running time for players of Australia, which is 28.1 seconds (Bloomfield, Ackland, \& Elliot, 1994).

The tests used in this study are good indicators of explosivity, speed and agility that are very important for success in basketball, due to the need to suppress the opponent, the short duration of the attack ( 24 seconds) and the constant change in the direction of running in relation to the position of the ball. Therefore, modern players must possess these characteristics at a very high level, as this is the only way to satisfactorily respond to the demands of the game (Popovic, Akpinar, Jaksic, Matic, \& Bjelica, 2013; Masanovic, T. Bavcevic, \& I.

\section{Acknowledgements}

There are no acknowledgements.

\section{Conflict of Interest}

The authors declare that there are no conflicts of interest.

Received: 16 August 2019| Accepted: 19 September 2019 | Published: 01 February 2020

\section{References}

Alemdaroglu, U. (2012). The Relationship between Muscle Strength, Anaerobic Performance, Agility, Sprint Ability and Vertical Jump Performance in Professional Basketball Players. Journal of human kinetics, 31(1), 99-106.
Bavcevic, 2019; Gardasevic, Bjelica, Corluka, \& Vasiljevic, 2019; Gardasevic, Bjelica, \& Vasiljevic, 2019; Krespi, Sporis, \& Popovic, 2019; Gardasevic \& Bjelica, 2020). Based on the mentioned results, we can still conclude that players who play in the First League of Montenegro and the Super League of Serbia have high motor potential. The fact that the measurement was performed before the start of the second part of the competitive season certainly influences the results, and it is to be expected that the results during the competitive period would be far better.

The main goal of this research was to determine whether the players from Montenegro have good motor potential, i.e., are they lagging behind the players from Serbia in terms of motor abilities, who achieve significant results at the highest international competitions. The data of descriptive statistics show that the players of both leagues have approximate mean values of the analysed variables, which is not surprising because they are players of the highest quality teams of the mentioned competition in Montenegro and Serbia, where there is a high concentration of quality players. The results of the t-test showed that a statistically significant difference in motor abilities between basketball players of the First League of Montenegro and Super League of Serbia exists only in one of the tested variables, the throwing of the basketball ball from the chest, and that difference is in favour of the players from Montenegro. Based on all this, we can conclude that these are basketball players who show good motor potential, and that Montenegrin basketball players do not lag behind Serbian basketball players when it comes to motor abilities. This confirms the good process of selection and quality preparedness of the basketball players of Montenegro, that is, the good basic and specific motor abilities that are necessary for a successful training and competitive process. Based on that, we can conclude that the reasons why the selection and teams from Montenegro achieve lower results than the selection and teams from Serbia, should be searched for in some other parameters, which also determine the success in basketball.

Moreover, these results can serve as model parameters in estimated variables for other players of the same rank of competition in Montenegro and Serbia, as well as for comparison with results obtained in other similar studies. It should be noted that players who want to play successfully in the league where the highest quality of basketball is played must have the characteristics set by the standards for this sport, which of course is reflected in the motor quality that the players possess (Vukasevic, Mitrovic, Zivanovic, \& Masanovic, 2019). Limitations of this study are the small sample of respondents (two teams from the top of the standings, two teams from the middle of the standings, and two teams from the bottom of the standings would be a representative sample).

Arifi, F., Bjelica, D., \& Masanovic, B. (2019). Differences in anthropometric characteristics among junior soccer and handball players. Sport Mont, 17(1), 45-49. doi: 10.26773/smj. 190208

Balaban, V. (2018). The relationship between objectively measured physical activity and fundamental motor skills in 8 to 11 years old children from the Czech Republic. Montenegrin Journal of Sports Science and Medicine, 7(2), 11-16. doi: 10.26773/mjssm.180902

Berria, M., Bachir, K., Nour Eddine, S., \& Adel, B. (2018). Study of LDH adaptations associated with the development of Speed endurance in basketball players U19. International Journal of Applied Exercise Physiology, 7(3), 35-43. https://doi.org/10.30472/ijaep.v7i3.270

Bjelica, D. (2005). Systematization of sports disciplines and sports training [Sistematizacija sportskih disciplina $i$ sportski trening]. Podgorica: 
Montenegrin Sports Academy.

Bjelica, D. (2006a). Sports training [Sportski trening]. Podgorica: Montenegrin Sports Academy.

Bjelica, D. (2006b). Theoretical basics of physical and nutritional education [Teorijske osnove tjelesnog $i$ zdrastvenog obrazovanja]. Podgorica: Montenegrin Sports Academy.

Bjelica, D., Popović, S., \& Gardašević, J. (2016). Dependence of basketball repulsion on the pressure within this sport. Journal of Physical Education and Sport, 16(1), 125-131. doi:10.7752/jpes.2016.01021

Bloomfield, J., Ackland, T., \& Elliot, B. (1994). Applied Anatomy and Biomechanics in Sport. Melburne: Blackwell.

Chaouachi, A., Brughelli, M., Chamari, K., Levin, G., Abdelkrim, N.B., Laurencelle, L., \& Castagna, C. (2009). Lower Limb Maximal Dynamic Strength and Agility Determinants in Elite Basketball Players. The Journa of Strength \& Conditioning Research, 23(5), 1570-1577.

Delextrat, A., \& Cohen, D. (2009). Strength, Power, Speed, and Agility of Women Basketball Players According to Playing Position. Journal of Strength and Conditioning Research, 23(7), 1974-1981. doi: 10.1519/ JSC.0b013e3181b86a7e

Dogan, I., \& Ersoz, Y. (2019). The important game-related statistics for qualifying next rounds in Euroleague. Montenegrin Journal of Sports Science and Medicine, 8(1), 43-50. doi: 10.26773/mjssm.190307

Gardasevic, J. \& Bjelica, D., (2020). Body composition differences between football players of the three top football clubs. International Journal of Morphology, 38(1), 153-158.

Gardasevic, J., \& Bjelica, D. (2019). Shooting ball accuracy with u16 soccer players after preparation period. Sport Mont, 17(1), 29-32. doi: 10.26773/ smj. 190205

Gardasevic, J., Akpinar, S., Popovic, S., \& Bjelica, D. (2019). Increased Perceptual and Motor Performance of the Arms of Elite Water Polo Players. Applied Bionics and Biomechanics, 6763470. Gardasevic, J., Bjelica, D., \& Corluka, M. (2018). The impact of the preparation period on endurance at football players U16. Sport Mont, 16(1), 21-24. doi: 10.26773/smj.180204

Gardasevic, J., Bjelica, D., Corluka, M., \& Vasiljevic, I. (2019). Elite football players from bosnia and herzegovina and kosovo and their body composition. Sport Mont, 17(2), 75-79. doi: 10.26773/smj.190613

Gardasevic, J., Bjelica, D., \& Vasiljevic, I. (2019). Morphological Characteristics and Body Composition of Elite Soccer Players in Montenegro. International Journal of Morphology, 37(1), 284-288.

Gardasevic, J., Bjelica, D., \& Corluka, M. (2018). The impact of the preparation period on endurance at football players U16. Sport Mont, 16(1), 21-24. doi: 10.26773/smj.180204

Gardašević, J., Georgiev, G., \& Bjelica, D. (2012). Qualitative changes of basic motor abilities after completing a six-week training programme. Acto Kinesiologica, 6(1), 70-74.

Gjonbalaj, M., Georgiev, G., \& Bjelica, D. (2018). Differences in Anthropometric Characteristics, Somatotype Components, and Functional Abilities Among Young Elite Kosovo Soccer Players Based on Team Position. International Journal of Morphology, 36(1), 41-47.

Gusic, M., Popovic, S., Molnar, S., Masanovic, B., \& Radakovic, M. (2017). Sport-Specific Morphology Profile: Differences in Anthropometric Characteristics among Elite Soccer and Handball Players. Sport Mont 15(1), 3-6.

Hoffman, J.R. (2006) Norms for fitness, performance and health. Champaign, Ilinois: Human Kinetics.

Jakovljevic, S., Karalejic, M., Pajic, Z., \& Mandic, R. (2011). Acceleration and speed of change of direction and the way of movement of quality basketball players. Physical Culture, 65(1), 16-23.

Karalejić, M., \& Jakovljević, S. (1998). Testing and measuring in basketball [Testiranje i merenje u košarci]. Beograd: Basketball Association of Serbia.
Krespi, M., Sporis, G., \& Popovic, S. (2019). Exponential versus linear tapering in junior elite soccer players: effects on physical match performance according to playing positions. Montenegrin Journal of Sports Science and Medicine, 8(1), 17-22. doi: 10.26773/mjssm.190303

Malacko, J. (2000). Basics of sports training [Osnove sportskog treninga]. Beograd: Sports Academy.

Masanovic, B. (2018). Comparative study of anthropometric measurement and body composition between junior basketball and volleyball players from Serbian national league. Sport Mont, 16(3), 19-24. https://doi. org/10.26773/smj.181004

Masanovic, B. (2019). Comparative Study of Morphological Characteristics and Body Composition between Different Team Players from Serbian Junior National League: Soccer, Handball, Basketball and Volleyball. International Journal of Morphology, 37(2), 612-619.

Masanovic, B., Bavcevic, T., \& Bavcevic, I. (2019). Comparative study of anthropometric measurement and body composition between junior soccer and volleyball players from the Serbian national league. Sport Mont 17(1), 9-14. doi: 10.26773/smj.190202

Matković, B.R., Matković, B., \& Knjaz, D. (2005). Physiology of basketball games [Fiziologija košarkaške igre]. Hrvatski športskomedicinski vjesnik, 20(2), 113-124.

Milanović, L., Jukić, I., \& Marković, G. (2004). Differences in the level of fitness preparation of the Croatian and Japanese representations. In Proceedings 13. Croatian Kinesiology Summer Schools (186-190). Zagreb: Faculty of Kinesiology.

Narazaki, K., Berg, K., Stergiou, N., \& Chen, B. (2009). Physiological demands of competitive basketball. Medicine \& Science in Sports, 19(3), 425-432. doi: 10.1111/j.1600-0838.2008.00789.x

Popovic, S., Akpinar, S., Jaksic, D., Matic, R., \& Bjelica, D. (2013). Comparative Study of Anthropometric Measurement and Body Composition between Elite Soccer and Basketball Players. International Journal of Morphology 31(2), 461-467.

Popovic, S., Bjelica, D., Jaksic, D., \& Hadzic, R. (2014). Comparative Study of Anthropometric Measurement and Body Composition between Elite Soccer and Volleyball Players. International Journal of Morphology, 32(1), 267-274.

Saavedra, J.M., Porgeirsson, S., Kristjansdottir, H., Halldorsson, K., Guðmundsdottir, M.L., \& Einarsson, I.P. (2018). Comparison of training volumes in different elite sportspersons according to sex, age, and sport practised. Montenegrin Journal of Sports Science and Medicine, 7(2), 37-42. doi: $10.26773 / \mathrm{mjssm} .180906$

Sermaxhaj, S., Popovic, S., Bjelica, D., Gardasevic, J., \& Arifi, F. (2017). Effect of recuperation with static stretching in isokinetic force of young football players. Journal of Physical Education and Sport, 17(3), 1948-1953. doi: 10.7752/jpes.2017.03191

Shalfawi, S.A.I., Sabbah, A., Kailani, G., Tønnessen, E., \& Enoksen, E. (2011) The Relationship between Running Speed and Measures of Vertical Jump in Professional Basketball Players: A Field-Test Approach. The Journal of Strength \& Conditioning Research, 25(11), 3088-3092.

Trninic, S., Perica, A., \& Dizdar, D. (1999). Set of criteria for the actual quality evaluation of the elite basketball players. Collegium Antropologicum, 23(2), 707-721.

Valdés-Badilla, P.A., Godoy-Cumillaf, A.E.R., Herrera-Valenzuela, T.N., \& Ramírez-Campillo, R. (2015). Perfil Antropométrico y Condición Física de Jugadores Veteranos de Básquetbol. International Journal of Morphology, 33(1), 285-290. https://dx.doi.org/10.4067/S0717-95022015000100045

Vukasevic, V., Mitrovic, M., Zivanovic, N., \& Masanovic, B. (2019). Comparative Study of Motor Ability between Basketball Players from Second Leagues in Montenegro and Serbia. Journal of Antropology of Sport and Physical Education, 3(1), 13-7. 